\title{
SQUIRE after one year
}

\section{David P Stevens}

\section{DEVELOPMENT OF SOUIRE-THE IMPERATIVE FOR SCHOLARLY PUBLICATION}

Gaps in the quality of healthcare, characterised over a decade ago as a chasm, ${ }^{1}$ continue to demand systematic resolution. Local improvement initiatives are essential to better, safer care of patients, but the spread of such local improvement widely to other settings requires the scholarly publication that has always resided at the heart of science-based healthcare. Moreover, as increasing numbers of clinical specialties embrace the imperative for healthcare improvement and patient safety, a recognisable format for scholarly publication can provide common ground for the shared new knowledge. ${ }^{2}$ The SQUIRE publication guidelines were developed in an effort to contribute to the expanding scholarship of healthcare improvement.

Similar to scholarly publication guidelines for other fields (e.g. CONSORT guidelines for randomised controlled trials), SOUIRE was developed to provide the critical elements of scholarly reports as a common framework for authors, editors and readers. They were originally promulgated as a draft in QSHC in 2005. ${ }^{4}$ That draft was followed by strategic efforts directed at its refinement-road-testing the draft guidelines by authors who used them for published reports, a conference of authors and editors to distil their content and format and a Delphi process, which invited more than 50 colleagues to contribute to their revision. That resulting product-SOUIRE-and a description of its development were reported in a supplement to QSHC in October 2008. ${ }^{3}$

\section{EDITORS AND AUTHORS AS STAKEHOLDERS}

The SQUIRE initiative sought to include editors as stakeholders. This was based on the assumption that editors who would acknowledge a common foundation for scholarly reporting could provide broader opportunities for publication of valuable improvement work. In the year since their publication, the Guidelines have been republished in 11 journals (Box), with most of those journals inviting the use of

Correspondence to: Dr David P Stevens, Quality Literature Program, Dartmouth Institute for Health Policy and Clinical Practice, 30 Lafayette Street, Lebanon, NH 03766, USA; david.p.stevens@dartmouth.edu
SQUIRE for scholarly healthcare quality improvement submissions.

In addition, the development group also sought to facilitate authors' use of SQUIRE. Such efforts have included a SQUIRE website that was developed to provide authors guidance for their use $e^{5}$; two online blogs that are associated with this site to describe the experience of authors as they use the guidelines to craft their scholarly papers; and numerous conferences and workshops that have addressed their use. Generally, authors, editors and reviewers have found that SQUIRE offers a uniform definition for essential elements such as context, validity, transferability, and others. ${ }^{6}$

\section{A CALL FOR RESEARCH ON THE ROLE AND VALUE OF SOUIRE}

Now that SQUIRE is increasingly a part of the scholarly discourse that surrounds healthcare quality improvement, is there additional potential for its expanded contribution to scholarly publication, and how might that be assessed? Here are several questions to frame such inquiry.

- 1. Does SQUIRE result in more and, importantly, more valuable scholarly publication in healthcare improvement? How can this be measured?

- 2. The original SQUIRE report suggested that tests of SQUIRE, similar to tests of other publication guidelines, would benefit from evaluation of their contribution to accuracy and transparency of reports. ${ }^{3}$ Can the

\section{Box: Eleven scholarly journals that have published the SQUIRE Guidelines as of October 2009}

American Journal of Critical Care American Journal of Nursing Annals of Internal Medicine British Medical Journal Canadian Journal of Diabetes Clinical Journal of Oncology Nursing Joint Commission Journal on Quality and Patient Safety Journal of General Internal Medicine Journal of Nursing Care Quality Quality and Safety in Health Care Spine stakes be raised even higher? Does the use of SQUIRE ultimately result in better, safer care for patients? How can this be documented?

- 3. Context is generally viewed as a confounder in randomised controlled trials. On the other hand, the authors of SQUIRE have made the argument that the description and role of context are of central importance to research in healthcare improvement. ${ }^{3}$ How can this be measured and demonstrated with acceptable validity?

- 4. Might SQUIRE contribute to design of better improvement studies? How can that be demonstrated?

- 5. SQUIRE is the product of considerable distillation by an extended consensus process. ${ }^{2}$ Nevertheless, can it be further simplified? Which SQUIRE components must always be included in a scholarly report? Conversely, are some components of relatively less importance, and in what settings?

- 6. Where do quality improvement reports and SQUIRE fit in the spectrum of scholarly publication? ${ }^{8}$ What is the relative role for each?

These questions and others ${ }^{9}$ offer opportunities for authors, reviewers and editors to contribute to this discussion. The editors of QSHC invite reports that address these questions as we endeavour to improve the clarity and relevance of scholarly improvement publication.

Competing interests: Declared. DPS is editor-in-chief of Quality and Safety in Health Care. He is also a member of the SQUIRE Development Group.

Qual Saf Health Care 2009;18:322.

doi:10.1136/qshc.2009.037648

\section{REFERENCES}

1. Institute of Medicine. Crossing the quality chasm: a new health system for the twenty-first century. Washington (DC): National Academies Press, 2001.

2. Rubenstien LV, Hempel S, Farmer MM, et al. Finding order in heterogeneity: types of quality-improvement intervention publications. Qual Saf Health Care 2008;17:403-8.

3. Davidoff $F$, Batalden $P$, Stevens D, et al, the SOUIRE Development Group. Publication guidelines for quality improvement in health care: evolution of the SQUIRE project. Qual Saf Health Care 2008:17:i3-9.

4. Davidoff F, Batalden P. Toward stronger evidence on quality improvement: draft publication guidelines: the beginning of a consensus project. Qual Saf Health Care 2005; 14:314

5. SOUIRE website. http://squire-statement.org/ (accessed 10 Sept 2009).

6. Sox H. Improving the quality of reporting studies of quality improvement: the SQUIRE Guidelines. Ann Int Med 2008;149:683.

7. Pronovost $\mathbf{P}$, Wachter R. Proposed standards for quality improvement research and publication: one step forward and two steps back. Qual Saf Health Care 2006;15:152-3

8. Thomson RG, Moss FM. QIR and SQUIRE: continuum of reporting guidelines for scholarly reports in healthcare improvement. Qual Saf Health Care 2008;17:110-2.

9. Stevens DP, Thomson R. SQUIRE arrives - with a plan for its own improvement. Qual Saf Health Care 2008;17:11-2. 